\title{
Searching For Prediabetes before Diabetes
}

\section{Gian Piero Carnevale Schianca, Mattia Bellan*, Michela Gentile, Antonello Gibbin, Alessandro Gualerzi, Serena Favretto, Ettore Bartoli and Mario Pirisi} University of Eastern Piedmont UPO, Department of Translational Medicine and Internal Medicine Division, AOU "Staff of Charity", Novara, Italy "Corresponding author: Bellan M, University of Eastern Piedmont UPO, Department of Translational Medicine and Internal Medicine Division, AOU "Staff of Charity", Novara, Italy, Tel: +390321/3733966; E-mail: bellanmattia@yahoo.it

Rec date: April 1, 2016; Acc date: April 27, 2016; Pub date: April 29, 2016

Copyright: ( 2016 Carnevale Schianca PG, et al. This is an open-access article distributed under the terms of the Creative Commons Attribution License, which permits unrestricted use, distribution, and reproduction in any medium, provided the original author and source are credited.

\section{Abstract}

Type 2 Diabetes Mellitus (T2DM) and pre diabetes prevalence is increasing worldwide at an alarming rate. Though many risk factors have been identified, the most appropriate strategy to identify when and who should undergo a more accurate screening, which could allow an earlier diagnosis and a more efficient prevention of complications, is still a matter of debate.

In this review we present data from a cohort of 2126 asymptomatic non diabetic subjects, who underwent an Oral Glucose Tolerance Test (OGTT). We have discussed our results sub-classifying our population according to the risk factors for diabetes development previously proposed by the American Diabetes Association.

According to our data, OGTT is able to identify a substantial proportion of subjects with prediabetic conditions who, if untreated, could progress to overt T2DM and potentially encounter serious health problems, even in non-at risk subgroups, such as subjects with a normal fasting glucose, who have a normal lipid profile and arterial pressure, who do not have a familiar history of diabetes and who do not fulfil classification criteria for metabolic syndrome.

Interestingly, a further proportion of subjects fulfil OGTT criteria for diagnosis of T2DM in each of these subgroups. Therefore, we believe that OGTT execution should be advocated as a screening test in asymptomatic populations to search prediabetes before diabetes.

Keywords: Type 2 diabetes mellitus; OGTT; Impaired fasting glucose (IFG); Impaired glucose tolerance (IGT)

\section{Introduction}

Type 2 diabetes mellitus (T2DM), strongly associated with microvascular and macrovascular complications, is increasing at an alarming rate worldwide [1] and, consequently, the estimated cost of its treatment, including that of related complications, is likely to increase dramatically [2].

The natural history of T2DM involves a rather long period, called prediabetes, in which defects in insulin sensitivity and secretion may be detected. Prediabetes, defined as impaired glucose tolerance (IGT) and/or impaired fasting glucose (IFG), is a major risk factor for development of T2DM. In addition, IGT has been associated with an increased risk of cardiovascular morbidity and mortality.

Prospective studies have established that the implementation of lifestyle interventions and/or pharmacologic treatment can prevent/ delay the onset of diabetes in high-risk subjects [3-6] resulting in a higher rate of diabetes remission, and/or in delayed need of diabetes medications in newly diagnosed subjects [7].

By the time T2DM is diagnosed, many patients already suffer from microvascular complications [7,8]; therefore, early recognition is critical. Strategies to identify individuals at increased risk of developing T2DM or affected by unknown diabetes do, indeed, limit complications and lower costs. How to plan these preventive strategies?
All clinical trials designed to investigate the possibility of delaying the onset of T2DM were focused on patients with IGT, or both IGT and IFG. IFG is defined as a fasting (at least 8 hours) plasma glucose (FPG) level $\geq 100$ and $<126 \mathrm{mg} / \mathrm{dl}$, whereas IGT as a glucose level $\geq$ 140 and $<200 \mathrm{mg} / \mathrm{dl} 2$ hours after a 75 -g oral glucose tolerance test (OGTT) [9].

Based on data from the National Health and Nutrition Examination Survey, the prevalence of subjects with prediabetes increased progressively from 1999 to 2010, reaching an alarming 36\% in subjects older than 18 [10]; it is estimated that nearly $60 \%$ of patients with T2DM had prediabetes 5 years before diagnosis [11].

Thus, screening asymptomatic populations is appropriate, such that the American Diabetes Association (ADA) [8] suggests executing OGTT in individuals who are overweight $(\mathrm{BMI} \geq 25)$ and have one or more of other risk factors such as age $\geq 45$ years, family history of T2DM, habitual physical inactivity, particular ethnicity, previously identified IFG or IGT, history of gestational diabetes, hypertension, HDL-cholesterol $\leq 35 \mathrm{mg} / \mathrm{dl}$ and/or a triglyceride (TG) level $\geq 250$ $\mathrm{mg} / \mathrm{dl}$, polycystic ovary syndrome, history of vascular disease [8].

These risk factors are so common that in very few individuals the OGTT would not be indicated, to the point that it should be performed much more frequently. However, this is not done as there is no uniform consensus on its usefulness $[12,13]$. OGTT is time consuming and unsatisfactorily reproducible [14]. This is the reason why ADA requires a second OGTT to confirm a diagnosis of diabetes and introduced the glycated haemoglobin $(\mathrm{HbAlc})$ for diagnosing the alterations in glucose metabolism [15]. 
Citation: Schianca GPC, Bellan M, Gentile M, Gibbin A, Gualerzi A, et al. (2016) Searching For Prediabetes before Diabetes. Gen Med (Los Angeles) 4: 237. doi:10.4172/2327-5146.1000237

Page 2 of 5

Almost half of patients remain undiagnosed because of the lack of symptoms $[8,16]$. This is an even more compelling reason to routinely perform OGTT, that detects both prediabetes, thus allowing a beneficial early treatment [3-7], and overt T2DM. In this opinion paper, we have reviewed the literature to verify the clinical impact of OGTT; we also report the results from a cohort of 2126 asymptomatic non diabetic subjects attending our metabolic diseases clinic. We will discuss these results in relation to different risk factors, including some of those suggested by ADA [8] (Table 1).

\section{OGTT in action}

\begin{tabular}{|c|c|}
\hline Age (years) & $52.6 \pm 14.2$ \\
\hline BMI $\left(\mathrm{kg} / \mathrm{m}^{2}\right)$ & $28.5 \pm 5.7$ \\
\hline Waist Circumference $(\mathrm{cm})$ & $93.9 \pm 14.2$ \\
\hline FPG (mg/dl) & $96.5 \pm 12.1$ \\
\hline Post-OGTT Plasma Glucose (mg/dl) & $120.8 \pm 41.9$ \\
\hline Age $\geq 45$ years $(\mathrm{Y} / \mathrm{N})$ & $1534 / 592$ \\
\hline Gender (M/F) & $953 / 1173$ \\
\hline Smoke $(\mathrm{Y} / \mathrm{N})$ & $799 / 1327$ \\
\hline Post-menopause (Y/N) & $716 / 457$ \\
\hline Family history of diabetes $(\mathrm{Y} / \mathrm{N})$ & $588 / 1281$ \\
\hline Family history of CV disease $(\mathrm{Y} / \mathrm{N})$ & $161 / 1491$ \\
\hline High Waist Circumference $^{*}(\mathrm{Y} / \mathrm{N})$ & $954 / 784$ \\
\hline $\mathrm{BMI} \mathrm{kg} / \mathrm{m}^{2} \geq 25(\mathrm{Y} / \mathrm{N})$ & $1533 / 593$ \\
\hline $\mathrm{BMI} \mathrm{kg} / \mathrm{m}^{2} \geq 30(\mathrm{Y} / \mathrm{N})$ & $717 / 1409$ \\
\hline Metabolic Syndrome (Y/N) & $805 / 1297$ \\
\hline Hypertension $(\mathrm{Y} / \mathrm{N})$ & $1580 / 546$ \\
\hline HDL-cholesterol $\leq 35$ mg/dl $(\mathrm{Y} / \mathrm{N})$ & $161 / 1932$ \\
\hline Triglycerides $\geq 250$ mg/dl (Y/N) & $161 / 1933$ \\
\hline
\end{tabular}

Table 1 shows the clinical data of our cohort. The majority of patients were females $(\mathrm{n}=1173,55.2 \%), 61.1 \%(\mathrm{n}=716)$ postmenopausal.

Out of the entire population, 799 (37.6\%) were active smokers, 954 (54.9\%) had a waist circumference $\geq 102 \mathrm{~cm}$ in males $(\geq 88$ in females), 1553 (70.1\%) had a BMI $\geq 25$ and $717(33.8 \%) \geq 30$.

Essential hypertension was present in $74.3 \%(\mathrm{n}=1580), 31.5 \%(\mathrm{n}=$ $588)$ had a family history of T2DM, 9.7\% $(n=161)$ had a history of cardiovascular disease, 7.7\% $(\mathrm{n}=161)$ had HDL-cholesterol $\leq 35$ $\mathrm{mg} / \mathrm{dl}, 7.7 \%(\mathrm{n}=161)$ had $\mathrm{TG} \geq 250 \mathrm{mg} / \mathrm{dl}, 72.1 \%(\mathrm{n}=1534)$ were older than 45 years and $38.3 \%(n=805)$ fulfilled the diagnosis of Metabolic Syndrome (MS) in agreement to ATPIII criteria [17].

OGTT was compatible with normal glucose tolerance (NGT) only in half of our population (1123 subjects; $52.8 \%$ ), while 472 subjects (22.2\%) had isolated IFG, 167 (7.9\%) isolated IGT, $241(11.3 \%)$ combined IFG/IGT and $123(5.8 \%)$ newly diagnosed T2DM. Interestingly, 34/123 T2DM patients (27.6\%) had a FPG $<100 \mathrm{mg} / \mathrm{dl}$.

\section{OGTT in relation to the physical conditions, life style and family history}

The alarming upsurge of T2DM in the world is accompanied by a similar rise in obesity and physical inactivity [1], therefore any intervention on lifestyle may bear positive effects not only on the course of diabetes, but also on its prevention [3-5,7] (Table 2).

Table 2 shows that OGTT was abnormal in $55.6 \%$ of subjects with a family history of T2DM, $63.4 \%$ of subjects with a history of previous cardiovascular events, $52.4 \%$ of subjects aged $\geq 45$ years, $50.1 \%$ of postmenopausal women, $49.7 \%$ of smokers and in $57.7 \%$ of obese subjects $(\mathrm{BMI} \geq 30)$. These same rate sequence in subjects without risk factors were $45.2 \%, 48.6 \%, 33.8 \%, 35.9 \%, 45.7 \%$ and $41.8 \%$ respectively.

A family history of diabetes is associated to an abnormal OGTT and reflects genetic susceptibility; however, although having a family history of T2DM is associated with better awareness of diabetes risk and participation to diabetes screening [18], the presence of a positive family history did not affect the result of lifestyle intervention in IGT subjects [19].

The strong relationship between abnormalities in glucose homeostasis and cardiovascular disease [20] is well known and, as 
Page 3 of 5

expected, in our population $63.4 \%$ of subjects with a positive history of cardiovascular events had an impaired OGTT. Surprisingly, on the other hand, even in absence of such a medical history, OGTT allows the diagnosis of prediabetes or T2DM in $48.6 \%$ of cases.

Aging and post-menopause are associated with worsening glucose homeostasis [15,21]. However, there are convincing data that the feared global pandemic of T2DM will not spare young people [22]. Data presented in this paper are eloquent: more than $35 \%$ of subjects younger than 45 and of pre-menopausal women have an abnormal OGTT.
Smoking is known to be associated with an increased risk of T2DM $[23,24]$ and also to magnify its deleterious effect when combined with other risk factors [25]. However, in the US, smoking prevalence among people with T2DM and IFG has not changed and it is comparable to non-diabetic subjects [26]. Although tobacco control efforts should be intensified among population at high risk of complications and mortality, OGTT should be performed irrespective of smoking behaviour.

\begin{tabular}{|c|c|c|c|c|}
\hline \multicolumn{2}{|l|}{ Risk factor } & \multirow{2}{*}{$\begin{array}{l}\text { NGT (n, \%) } \\
702(54.8)\end{array}$} & \multirow{2}{*}{$\begin{array}{l}\text { preDM (n, \%) } \\
514(40.1)\end{array}$} & \multirow{2}{*}{$\begin{array}{l}\mathrm{DM}(\mathrm{n}, \%) \\
65(5.1)\end{array}$} \\
\hline & No $(n=1281)$ & & & \\
\hline & Yes $(n=588)$ & $261(44.4)$ & $274(46.6)$ & $53(9.0)$ \\
\hline \multirow{2}{*}{$\begin{array}{l}\text { History of } \\
\text { Cardiovascular } \\
\text { disease }\end{array}$} & No $(n=1491)$ & $766(51.4)$ & $636(42.6)$ & $89(6.0)$ \\
\hline & Yes $(n=161)$ & $59(36.6)$ & $79(49.1)$ & $23(14.3)$ \\
\hline \multirow{2}{*}{ Age $\geq 45$ years } & No $(n=592)$ & $392(66.2)$ & $184(31.1)$ & $16(2.7)$ \\
\hline & Yes $(n=1534)$ & $731(47.6)$ & $696(45.4)$ & $107(7.0)$ \\
\hline \multirow{2}{*}{ Smokers } & No $(n=1327)$ & $721(54.3)$ & $533(40.2)$ & $73(5.5)$ \\
\hline & Yes $(n=799)$ & $402(50.3)$ & $347(43.4)$ & $50(6.3)$ \\
\hline \multirow{2}{*}{$\begin{array}{l}\text { Post-menopausal } \\
\text { condition }\end{array}$} & No $(n=457)$ & $293(64.1)$ & $147(32.2)$ & $17(3.7)$ \\
\hline & Yes (716) & $357(49.9)$ & $314(43.8)$ & $45(6.3)$ \\
\hline \multirow{3}{*}{ BMI } & $<25(\mathrm{n}=593)$ & $402(67.8)$ & $167(28.1)$ & $24(4.1)$ \\
\hline & $25-29.9(n=816)$ & $418(51.2)$ & $347(42.6)$ & $51(6.2)$ \\
\hline & $\geq 30(n=717)$ & $303(42.3)$ & $366(51.0)$ & $48(6.7)$ \\
\hline \multirow{2}{*}{ Hypertension } & No $(n=546)$ & $360(65.9)$ & $165(30.2)$ & $21(3.9)$ \\
\hline & Yes $(n=1580)$ & $763(48.3)$ & $715(45.2)$ & $102(6.5)$ \\
\hline \multirow{2}{*}{ Metabolic Syndrome } & No $(n=1297)$ & $902(69.5)$ & $349(27.0)$ & $46(3.5)$ \\
\hline & Yes $(n=805)$ & $210(26.1)$ & $518(64.3)$ & $77(9.6)$ \\
\hline \multirow{2}{*}{$\mathrm{HDL} \leq 35 \mathrm{mg} / \mathrm{dl}$} & No $(n=1932)$ & $1029(53.3)$ & $794(41.1)$ & $109(5.6)$ \\
\hline & Yes $(n=161)$ & $76(47.2)$ & $71(44.1)$ & $14(8.7)$ \\
\hline \multirow{2}{*}{$\mathrm{TG} \geq 250 \mathrm{mg} / \mathrm{dl}$} & No $(n=1933)$ & $1043(53.9)$ & $779(40.4)$ & $111(5.7)$ \\
\hline & Yes $(n=161)$ & $62(38.5)$ & $87(54.1)$ & $12(7.4)$ \\
\hline
\end{tabular}

Finally, if it is true that in obesity there is a higher prevalence of glucose abnormalities, it is not uncommon to find these alterations in subjects with normal BMI.

As shown in Table 2, though the prevalence of prediabetes and T2DM was very high in obese subjects $(\mathrm{BMI} \geq 30)$ and in case of overweight $(25<\mathrm{BMI}<30)$, it still remained at a remarkable level in subjects with normal BMI (respectively $28.1 \%$ and $4.1 \%$ ).

The adoption of lifestyle changes is mandatory and essential also in subjects with normal BMI and impaired OGTT.

\section{OGTT in hypertension}

Alterations of glucose metabolism are common in hypertension [27]. As shown in the (Table 2), over $50 \%$ of hypertensives had an abnormal OGTT. Of these, $12.5 \%$, corresponding to $6.5 \%$ of all hypertensives, received a new diagnosis of T2DM. As the coexistence of hypertension and T2DM is harmful [28], it should be investigated in order to take appropriate therapeutic measures. A tight control of blood pressure in patients with T2DM may achieve important reductions in diabetes-related morbidity and mortality and weight reduction lowers blood pressure while improving blood glucose and lipid levels [29,30]. 
The finding of a high prevalence of prediabetes in hypertension $(45.2 \%)$ is indisputable and should therefore be systematically sought by OGTT. The detection of prediabetes in hypertensives is crucial to develop strategies for cardiovascular protection intended to diminish the consequences of an accelerated development of diabetes, together with its cardiovascular and renal deleterious effects [31], through intensive lifestyle management and pharmacologic therapies [32].

Anyway, even in the absence of hypertension, OGTT demonstrates its ability to detect a fair proportion of subjects with prediabetes (30.2\%) and T2DM (3.9\%).

\section{OGTT in MS and atherogenic dyslipidemia}

The prevalence and severity of MS are rising dramatically [17,33]. It is easy detection using ATPIII criteria [17] is a simple tool to stratify cardiovascular risk. FPG is one of the five criteria used by ATPIII and recently its cut-off value was lowered from 110 to $100 \mathrm{mg} / \mathrm{dl}$ [17] in agreement with ADA criteria for the diagnosis and classification of T2DM $[9,15]$.

Though this cut-off change was introduced aiming to include in MS definition the majority of subjects with abnormal glucose metabolism, authoritative studies have established that IFG adds very few to IGT in predicting incident T2DM [34].

As shown in Table 2, 73.9\% of patients with MS had an impaired OGTT; of these, $12.9 \%$ fulfilled the diagnostic criteria of T2DM. In turn, T2DM patients with MS bear a cardiovascular risk significantly higher than NGT subjects, also when affected by MS [34]. Thus, the attention to MS is important, but it may not be sufficient, since an abnormal OGTT is an independent cardiovascular risk factor.

Table 2 also shows the performance of OGTT in relation to the presence or absence of two additional risk factors for T2DM listed by ADA [8]: a TG level $\geq 250 \mathrm{mg} / \mathrm{dl}$ and HDL-cholesterol $\leq 35 \mathrm{mg} / \mathrm{dl}$. These are part of the classification criteria for MS though, in this case, their threshold values are more stringent [17].

High TG levels coupled to low HDL levels characterize the atherogenic dyslipidemia, a phenotype associated with increased cardiovascular risk [35].

As evident in Table 2, OGTT was abnormal in $61.5 \%$ of subjects with $\mathrm{TG} \geq 250 \mathrm{mg} / \mathrm{dl}$ and in $52.8 \%$ of subject with HDL-cholesterol $\leq$ $35 \mathrm{mg} / \mathrm{dl}$. In the absence of those risk factors, these percentages become $46.1 \%$ and $46.7 \%$, respectively. Even in this context, regardless of the risk factors considered, the OGTT confirms its usefulness in screening for T2DM and cardiovascular risk.

\section{Conclusion}

The OGTT, developed to determine the ability of an individual to maintain glucose homeostasis, can be considered a screening test not only for abnormal glucose metabolism, but also for cardiovascular risk stratification. Although dated, the OGTT may constitute a viable option to deal with the expected pandemic of T2DM.

In this review, the data shown are consistent with the concept that, wherever used, the OGTT is unerringly able to detect a substantial proportion of cardio metabolic risk that would otherwise be unrecognised.

In fact, the absence of the risk factors suggested by ADA is unable to rule out an alteration of glucose homeostasis; regardless of any risk factor considered, OGTT appears consistently able to identify a substantial proportion, at least $30 \%$, of subjects with impaired glucose metabolism that, if untreated, would encounter serious health problems, progressing to overt $\mathrm{T} 2 \mathrm{DM}$ and developing micro and macrovascular complications. Furthermore, prediabetes is burdened, per se, by an increased risk of diabetic retinopathy $[3,36]$ cardiovascular events [37] and sudden death [38].

It is obvious that the earlier the recognition will take place, the better the prevention will be. Recently, the benefits of a dietary intervention in subjects with newly diagnosed T2DM have been reported in patients with a mean FPG of $162 \pm 34 \mathrm{mg} / \mathrm{dl}$, indicating a delayed diagnosis [7]. An earlier detection would have yielded benefits far superior to those obtained with delayed treatment.

Furthermore, it is worth noting that, in our present study, all subjects with newly diagnosed T2DM had a FPG $<126 \mathrm{mg} / \mathrm{dl}$.

Therefore, we believe that our evidence demonstrates that OGTT should never be neglected and, as a matter of fact, its execution should be advocated as a screening test in asymptomatic populations to search for prediabetes before diabetes.

\section{References}

1. World Health Organization (WHO). Global report on diabetes. Geneva, 2016.

2. American Diabetes Association (2008) Economic costs of diabetes in the US in 2007. Diabetes Care 31: 1-20.

3. The Diabetes Prevention Program Research Group (2002) Reduction in the incidence of type 2 diabetes with lifestyle intervention or metformin. N Engl J Med 346: 393-403.

4. The Diabetes Prevention Program Research Group (2012). Long-term safety, tolerability, and weight loss associated with metformin in the Diabetes Prevention Program Outcomes Study. Diabetes Care 35: 731-737.

5. Stevens JW, Khunti K, Harvey R, Johnson M, Preston L, et al. (2015) Preventing the progression to type 2 diabetes mellitus in adults at high risk: a systematic review and network meta-analysis of lifestyle, pharmacological and surgical interventions. Diabetes Res Clin Pract 107: 320-31.

6. DeFronzo RA, Tripathy D, Schwenke DC, Banerji MA, Bray GA, et al. (2011) Pioglitazone for diabetes prevention in impaired glucose tolerance. N Engl J Med 364: 1104-1115.

7. Esposito K, Maiorino MI, Petrizzo M, Bellastella G, Giugliano D (2014) The effects of a mediterranean diet on the need for diabetes drugs and remission of newly diagnosed Type 2 diabetes: follow-up of a randomized trial. Diabetes Care 37: 1824-1830.

8. American Diabetes Association (2003) Screening for type 2 diabetes. Diabetes Care 26: S21-24.

9. American Diabetes Association (2008) Diagnosis and classification of diabetes mellitus. Diabetes Care 31: S55-60.

10. Bullard KM, Saydah SH, Imperatore G, Cowie CC, Gregg EW, et al. (2013) Secular changes in U.S. Prediabetes prevalence defined by hemoglobin A1c and fasting plasma glucose: National Health and Nutrition Examination Surveys 1999-2010. Diabetes Care 36: 2286-2293.

11. Unwin N, Shaw J, Zimmet P, Alberti K (2002) Impaired glucose tolerance and impaired fasting glycaemia: the current status on definition and intervention. Diabet Med 19: 708-723.

12. Kim DL, Kim SD, Kim SK, Park S, Song KH (2015) Is an oral glucose tolerance test still valid for diagnosing diabetes mellitus? Diabetes Metab J.

13. Meigs JB, Nathan DM, D’Agostino RB, Wilson PWF (2002) Fasting and postchallenge glycemia and cardiovascular risk: the framingham offspring study. Diabetes Care 25: 1845-1850. 
Citation: Schianca GPC, Bellan M, Gentile M, Gibbin A, Gualerzi A, et al. (2016) Searching For Prediabetes before Diabetes. Gen Med (Los Angeles) 4: 237. doi:10.4172/2327-5146.1000237

Page 5 of 5

14. Davidson MB (2002) Counterpoint: the oral glucose tolerance test is superfluous. Diabetes Care 25: 1883-1885.

15. American Diabetes Association (2012) Diagnosis and classification of diabetes mellitus. Diabetes Care 35: S64-71.

16. Beagley J, Guariguata L, Weil C, Motala AA (2014) Global estimates of undiagnosed diabetes in adults. Diabetes Res Clin Pract 103: 150-160.

17. Grundy SM, Cleeman JI, Daniels SR, Donato KA, Eckel RH, et al. (2005) Diagnosis and management of the metabolic syndrome: an American Heart Association/National Heart, Lung and Blood Institute Scientific Statement. Circulation 112: 2735-2752.

18. Baptiste-Roberts K, Gary TL, Beckles GLA, Gregg EW, Owens M, et al. (2007) Family history of diabetes, awareness of risk factors, and health behaviors among African Americans. Am J Public Health 97: 907-912.

19. Uusitupa MI, Cáková AS, Peltonen M, Eriksson JG, Lindström J, et al. (2011) Impact of positive family history and genetic risk variants on the incidence of diabetes the finnish diabetes prevention study. Diabetes Care 34: 418-423.

20. MilicevicZ, Raz I, Beattie SD, Campaigne BN, Sarwat S, et al. (2008) Natural history of cardiovascular disease in patients with diabetes. Role of hyperglycemia. Diabetes Care 31: S155-60.

21. Carnevale Schianca GP, Castello L, Rapetti R, Limoncini A, Bartoli E (2006) Insulin sensitivity: gender-related differences in subjects with normal glucose tolerance. Nutrition, Metabolism and Cardiovascular Diseases 16: 339-344.

22. Demmer RT, Zuk AM, Rosenbaum M, Desvarieux M (2013) Prevalence of diagnosed and undiagnosed type 2 diabetes mellitus among US adolescents: results from the continuous NHANES, 1999-2010. Am J Epidemiol 178: 1106-1113.

23. Foy CG, Bell RA, Farmer DF, Goff Jr. DC, Wagenknecht LE (2005) Smoking and incidence of diabetes among U.S. adults findings from the insulin resistance atherosclerosis study. Diabetes Care 28: 2501-2507.

24. InterAct Consortium: Spijkerman AM, van der A DL, Nilsson PM, Ardanaz E, Gavrila D, et al. (2014) Smoking and long-term risk of type 2 diabetes: the EPIC-InterAct study in European populations. Diabetes Care 37: 3164-3171.

25. Pan A, Wang Y, Talaei M, Hu FB (2015) Relation of smoking with total mortality and cardiovascular events among patients with diabetes mellitus: a meta-analysis and systematic review. Circulation 132: 1795-1804.

26. Clair C, Meigs JB, Rigotti NA (2013) Smoking behavior among US adults with diabetes or impaired fasting glucose. Am J Med 126: 15-18.

27. Carnevale Schianca GP, Fra GP, Steffanini M, Pogliani G, Marconi C, et al. (2014) Impaired glucose metabolism in hypertensive patients with/ without the metabolic syndrome. Eur J Intern Med 25: 477-481

28. Lastra G, Syed S, Kurukulasuriya LR, Manrique C, Sowers JR (2014) Type 2 diabetes mellitus and hypertension: an update. Endocrinol Metab Clin North Am 43: 103-122.

29. UK Prospective Diabetes Study Group (1998) Tight blood pressure control and risk of macrovascular and microvascular complications in type 2 diabetes. BMJ 317: 703-713.

30. American Diabetes Association Standards of medical care in diabetes 2011 (2011) Diabetes Care 34: S11-S61.

31. Segura J, Campo C, Ruilope LM, Rodicio JL (2005) Do we need to target 'prediabetic' hypertensive patients? J Hypertens 23: 2119-2125.

32. Hsueh WA, Orloski L, Wyne K (2010) Prediabetes: the importance of early identification and intervention. Postgrad Med 122: 129-143.

33. O'Neill S, O'Driscoll L (2015) Metabolic syndrome: a closer look at the growing epidemic and its associated pathologies. Obes Rev 16: 1-12.

34. Lorenzo C, Okoloise M, Williams K, Stern MP, Haffner SM (2003) The metabolic syndrome as predictor of Type 2 diabetes. The San Antonio Heart Study. Diabetes Care 26: 3153-3159.

35. Resnick HE, Howard BV (2002) Diabetes and cardiovascular disease. Annu Rev Med 53: 245-267.

36. Diabetes Prevention Program Research Group (2007) The prevalence of retinopathy in impaired glucose tolerance and recent-onset diabetes in the Diabetes Prevention Program Diabet Med 24: 137-144.

37. Chiasson J-L, Josse RG, Gomis R, Hanefeld M, Karasik A et al. (2003) For the STOP-NIDDM trial research group acarbose treatment and the risk of cardiovascular disease and hypertension in patients with impaired glucose tolerance. The STOP-NIDDM Trial. JAMA 290: 486-494.

38. Schatz IJ, Masaki K, Yano K, Chen R, Rodriguez BL, et al. (2001) Cholesterol and all-cause mortality in elderly people from the Honolulu Heart Program: a cohort study. Lancet 358: 351-355. 